Disponível em

http://www.anpad.org.br/rac

RAC, Curitiba, v. 14, n. 1, art. 6,

pp. 100-121, Jan./Fev. 2010

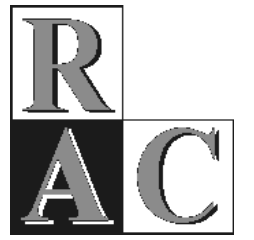

\title{
Gestão da Cooperação Empresa-Universidade: o Caso de uma Multinacional Brasileira
}

\author{
Management of Company-University Cooperation: a Brazilian Multinational Case
}

Priscila Rezende da Costa *

Doutoranda em Administração na FEA/USP. Pesquisadora Assistente no Núcleo PGT/USP, São Paulo/SP, Brasil.

Geciane Silveira Porto Doutora em Administração pela FEA/USP. Professora na FEA-RP/USP, Ribeirão Preto/SP, Brasil.

Diogenes Feldhaus Mestre pela Rutges University, Estados Unidos. Professor no IELUSC, Joinville/SC, Brasil.

* Endereço: Priscila Rezende da Costa

Av. Prof. Luciano Gualberto, 908, FEA 1, Piso Superior, Sala B 114, Núcleo PGT/USP, Cidade Universitária/USP, Butantã, São Paulo/SP, 05508-900. E-mail: priscilarc@ @earp.usp.br

Copyright @ 2010 RAC. Todos os direitos, inclusive de tradução, são reservados. É permitido citar parte de artigos sem autorização prévia desde que seja identificada a fonte. 


\title{
RESUMO
}

O objetivo deste trabalho é analisar como uma multinacional brasileira gerencia a cooperação com fontes externas de tecnologia, tais como universidades e institutos de pesquisa. Para tanto, realizou-se uma pesquisa qualitativa de natureza descritiva; como método, utilizou-se o estudo de caso, onde se estudou em profundidade a Empresa Brasileira de Compressores [Embraco]. Os resultados da pesquisa revelaram que a Embraco gerencia a cooperação com fontes externas de tecnologia, a partir de um modelo de gestão formal, integrado por onze práticas administrativas que são processadas linearmente. Estas práticas gerenciais são basicamente efetivadas seqüencialmente em três fases: a fase de pré-desenvolvimento da cooperação, na qual ocorre a definição dos projetos, a seleção dos parceiros e o planejamento das atividades; a fase de desenvolvimento da cooperação, onde os contratos são firmados, a infra-estrutura é organizada, e as atividades são executadas e acompanhadas; e a fase de pós-desenvolvimento da cooperação, na qual as atividades são avaliadas, o conhecimento é transferido, e a propriedade intelectual é garantida. Apenas as práticas de acompanhamento e de avaliação tendem a ocorrer de forma mais dinâmica, ao longo do processo de cooperação.

Palavras-chave: multinacional brasileira; gestão; cooperação empresa-universidade.

\begin{abstract}
This paper aims to examine how a Brazilian multinational manages cooperation with external sources of technology, such as universities and research institutes. To achieve this, qualitative research of a descriptive nature was performed and the case study method was used. Empresa Brasileira de Compressores [Embraco] was studied in depth. The survey results showed that Embraco manages cooperation with external sources of technology following a formal pattern of management, integrated by eleven administrative practices that are linearly processed. These management practices are basically carried out sequentially in three stages: the predevelopment of cooperation stage, which is the project definition, the partner selection and the activity planning; the cooperation development stage, in which contracts are signed, the infrastructure is organized and activities are implemented and monitored; and the cooperation post-development stage in which the activities are evaluated, knowledge is transferred and intellectual property is guaranteed. Only monitoring and evaluation practices tend to occur more dynamically through the cooperation process.
\end{abstract}

Key words: Brazilian multinational; management; university-enterprise cooperation. 


\section{INTRODUÇÃO}

Ao longo das últimas duas décadas, o conceito de inovação migrou do significado mais estreito de inovação de produtos e processos para um significado mais amplo de inovação organizacional e de mercado. A análise do processo inovador, antes focada somente na geração linear de novos saberes, também sofreu inúmeras mudanças e hoje aborda o desenvolvimento de novas formas de produzir, aplicar e distribuir o conhecimento, como, por exemplo, as parcerias tecnológicas firmadas entre empresas e universidades.

Incorporar as novas proposições do processo inovador, enfrentar a concorrência internacional e promover inovações tecnológicas tornam-se, portanto, tarefas complexas para os países em desenvolvimento como o Brasil. Esses desafios também são agravados pela incipiente preocupação das empresas locais com a propriedade intelectual, pelo baixo incentivo à fixação de doutores e mestres no setor empresarial e pela escassez propriamente dita de inovações (Brito-Cruz, 1999; Cassiolato \& Lastres, 2005; Chesnais, 1998; Edler, Krahmer, \& Reger, 2002; Fleury, 1999; Freeman, 1991; Motohashi, 2005; Segatto-Mendes, 2002; Sutz, 2000).

Desse modo, todas as formas de geração de sinergias para superar o atraso tecnológico das empresas brasileiras são positivas, sendo uma dessas formas a cooperação dos setores produtivos com a academia e a atuação das multinacionais enquanto instituições geradoras e difusoras de conhecimento e tecnologia. $\mathrm{O}$ crescimento de acordos cooperativos entre instituições de pesquisa e entidades empresariais representa, portanto, nova tendência colocada pela sociedade. $\mathrm{O}$ estudo desses arranjos, notadamente a sua estrutura e sua gestão, poderá contribuir para o desenvolvimento de modelos gerenciais inovadores, dando suporte ao conseqüente crescimento econômico e tecnológico dos países que buscam o desenvolvimento.

Diante desse contexto, este trabalho se propõe a analisar como uma multinacional brasileira gerencia a cooperação com fontes externas de tecnologia, tais como universidades e institutos de pesquisa. Especificamente, procurou-se (a) mapear a natureza das atividades desenvolvidas em parceria com universidades e institutos de pesquisa; (b) analisar as práticas administrativas utilizadas na gestão dessas atividades; e (c) caracterizar o modelo de gestão adotado na cooperação empresa-universidade.

A seguir são apresentados os preceitos teóricos que corroboram a pesquisa, a metodologia adotada, os resultados obtidos e, por fim, as considerações finais do trabalho.

\section{InOVAÇÃo E CoOPERAÇÃo TeCNOLÓGICA: Processos DinÂMICOS E INTERDEPENDENTES}

A tecnologia está associada a impactos socioeconômicos sobre uma comunidade, resultantes da aplicação de novos materiais, novos processos de fabricação, novos métodos e novos produtos nos meios de produção. Para que uma tecnologia criada seja transformada em inovação, essa tecnologia deve ser produzida pelos agentes econômicos, as empresas, disponibilizada para a sociedade e aceita por esta. O processo de inovação tecnológica envolve, então, todo o ciclo que compreende pesquisa básica, pesquisa aplicada, desenvolvimento, produção, marketing, venda, logística, pós-venda e todas as interações e realimentações possíveis entre essas fases (Cassiolato \& Lastres, 2005; Motohashi, 2005; Reis, 2004).

No tocante aos modelos de inovação tecnológica, Berkhout, Hartmann, Duin e Ortt (2006) desenvolveram o modelo cíclico da inovação $[\mathrm{MCI}]$, com a finalidade de elaborar um instrumento para a reforma contínua da ciência e da indústria. Esse modelo reflete a dinâmica dos processos econômicos e inovadores, e sua interação cíclica é a base para o controle moderno e é uma précondição para a flexibilidade operacional e a sustentabilidade. Uma característica fundamental do MCI 
é que a ciência não está no começo de uma corrente cuja extremidade é o mercado. Ambos, ciência e mercado, são partes de um processo criativo que não tem nenhum ponto fixo de início ou término, ou seja, no MCI, as descobertas científicas e as mudanças do mercado se influenciam mutuamente, continuamente e de maneira cíclica.

Etzkowitz e Leydesdorff (2000) sugerem um modelo que viabilize a formação de um padrão espiral de ligações, nos vários estágios do processo de inovação, que permita melhor compreender as relações que se estabelecem nas três esferas institucionais: universidade, empresa e governo. Esse modelo, denominado Triple Helix, é apresentado como uma proposta intermediária entre o livre mercado e o planejamento centralizado. A proposta é que o crescimento econômico futuro é dependente não apenas de novo ciclo de inovações, mas de nova estrutura para a inovação que ligue a pesquisa básica e a aplicada de forma cada vez mais próxima (Etzkowitz, 2004; Leydesdorff, Dolfsma, \& Panne, 2006; Leydesdorff \& Meyer, 2006). Dessa maneira, o modelo da tríplice hélice pode ser compreendido por meio de três estágios distintos.

a) $\mathrm{Na}$ Tríplice Hélice 1: as três esferas (universidade, indústria e governo) são definidas institucionalmente. A interação delas ocorre por meio de relações industriais, transferência de tecnologia e contratos oficiais, amplamente disseminados em países desenvolvidos e em desenvolvimento.

b) $\mathrm{Na}$ Tríplice Hélice 2: as esferas são definidas como diferentes sistemas de comunicação, consistindo em operações de mercado, inovação tecnológica e controle de interfaces. As interfaces geram novas formas de comunicação ligadas à transferência de tecnologia e apoiadas em uma legislação sobre patentes.

c) Na Tríplice Hélice 3: as esferas institucionais da universidade, indústria e governo, em acréscimo às funções tradicionais, assumem papéis uns dos outros. A universidade passa a ter desempenho quase governamental, como, por exemplo, organizadora da inovação tecnológica local ou regional.

Nesse conceito, o modelo de tríplice hélice é recursivo, ou seja, as interseções das esferas institucionais interferem na teoria e na prática. No tempo em que novos papéis são assumidos, alguns papéis são reforçados. Há troca de papéis, mas as instituições não desaparecem. Assim, a tríplice hélice modela nova forma de infra-estrutura de conhecimento, diferindo do modelo clássico de ciência, que é estável. Na concepção da tríplice hélice, os genes da inovação não são dados, mas aspectos reais que são construídos social e tecnicamente. A evolução econômica das modernas sociedades, com sua tendência de autotransformação e suas interações operacionais, levam a um rearranjo de suas configurações que interferem no processo de inovação (Etzkowitz, 2004; Leydesdorff et al., 2006; Leydesdorff \& Meyer, 2006).

Diante dessas discussões sobre o processo de inovação e as ligações dos setores de produção material e intelectual, surge o termo 'cooperação empresa-universidade', que pode ser genericamente definido como conjunto de interações que objetivam a produção de conhecimentos e que envolvem relações diretas ou indiretas entre empresas ou grupos de empresas e universidades/institutos de pesquisa. Esse conjunto de interações une a pesquisa básica, pesquisa aplicada e o desenvolvimento tecnológico, resultando no desenvolvimento do potencial tecnológico e científico dos parceiros envolvidos (Mora-Valentin, Montoro-Sanchez, \& Guerra-Martin, 2004; Schartinger, Rammer, Ficher, \& Frohlich, 2002).

No que se refere à efetivação da cooperação tecnológica, nota-se que as universidades e as empresas usam uma variedade de arranjos, a fim de viabilizar este fluxo dinâmico. Esses arranjos variam de acordo com a intensidade das relações pessoais, dos tipos de conhecimento transferidos e do sentido do fluxo do conhecimento. Do ponto de vista da empresa, o uso de arranjos distintos representa a variação das estratégias que asseguram a eficiência da pesquisa, garantem o acesso a tipos diferentes de conhecimentos científicos e tecnológicos e refletem diferenças na demanda de conhecimento em estágios diferentes da inovação (Laursen \& Salter, 2004; Schartinger et al., 2002).

Um modelo de gestão adequado aos diferentes arranjos de cooperação tecnológica envolve pontos 
chave, como os seguintes: a prospecção eficiente dos parceiros para assegurar o seu interesse efetivo ao longo da parceria; a ativa contribuição dos parceiros; o estabelecimento de uma gerência de projetos de qualidade; o ajuste dos objetivos das partes envolvidas; a comunicação efetiva ao longo da cooperação; e o monitoramento do progresso da parceria. Alguns fatores, como confiança, compromisso e continuidade, são também importantes no sucesso da colaboração tecnológica. Portanto, é decisivo criar uma ponte entre clientes (empreendedores/empresa) e fornecedores de conhecimento (cientistas) e desenvolver procedimentos gerenciais versáteis, que levem em consideração as necessidades, os interesses e as potencialidades de ambos os parceiros (Barnes, Pashby, \& Gibbons, 2002; Siegel, Waldman, Atwater, \& Link, 2003).

Corroborando essa perspectiva, Debackere e Veugelers (2005), afirmam que o desenvolvimento de uma estrutura adequada para a cooperação empresa-universidade exige uma atenção sobre os interesses acadêmicos e empresariais. Dessa forma, regulamentos transparentes sobre os direitos de propriedade intelectual se tornam elementos importantes à eficiência da cooperação. Ainda segundo os autores, deve-se optar por uma gerência descentralizada, pois essa opção implica liberdade para aproveitar as oportunidades da transferência de tecnologia, flexibilidade para gerenciar o uso dos rendimentos das atividades e dinamicidade para reverter os resultados dos trabalhos cooperativos em inovação.

A seguir, é apresentada uma síntese teórica dos procedimentos gerenciais utilizados ao longo das etapas de iniciação, execução e de finalização dos projetos cooperativos bem-sucedidos que foram discutidos na literatura por vários autores, como Bonaccorsi e Piccaluga (1994), Prabhú, (1999), Mora-Valentin (2000), Schartinger et al. (2002), Barnes et al. (2002), Siegel et al. (2003), MoraValentin et al. (2004), Laursen e Salter (2004) e Debackere e Veugelers (2005).

Tabela 1

\section{Etapa Inicial dos Projetos Cooperativos}

\begin{tabular}{|c|c|c|}
\hline \multicolumn{3}{|c|}{ ETAPA INICIAL DOS PROJETOS COOPERATIVOS } \\
\hline Subetapas & Procedimentos & Descrição \\
\hline \multirow[t]{3}{*}{$\begin{array}{l}\text { Condições } \\
\text { antecedentes } \\
\text { do projeto } \\
\text { para a } \\
\text { empresa }\end{array}$} & $\frac{\underline{\text { Importância do }}}{\frac{\text { projeto para a }}{\text { empresa }}}$ & $\begin{array}{l}\text { O projeto tem importância estratégica para a empresa. A empresa } \\
\text { identifica problemas persistentes com o uso dos seus produtos ou da } \\
\text { tecnologia atual; assim, opta por realizar inovações parciais ou completas } \\
\text { para reter ou desenvolver vantagem competitiva. }\end{array}$ \\
\hline & $\frac{\frac{\text { Motivações e }}{\text { condicionantes }}}{\underline{\text { da empresa }}}$ & $\begin{array}{l}\text { O projeto é essencial para que a empresa desenvolva e retenha a } \\
\text { liderança tecnológica no mercado e possa vislumbrar um crescimento } \\
\text { futuro, isso porque a tecnologia atual se torna cada vez mais inadequada } \\
\text { ou imprópria. A tecnologia nova advinda das parcerias tecnológicas } \\
\text { funciona como salto tecnológico para a empresa, uma vez que elas } \\
\text { proporcionam o compartilhamento de habilidades, recursos, riscos e } \\
\text { equipamentos. }\end{array}$ \\
\hline & $\begin{array}{l}\frac{\text { Escolha do }}{\text { parceiro }} \\
\text { acadêmico por } \\
\text { parte da empresa }\end{array}$ & $\begin{array}{l}\text { Ao optar pela parceria, inicia-se o processo de busca do parceiro, cuja } \\
\text { primeira opção é geralmente uma instituição de sua vizinhança imediata } \\
\text { (na mesma cidade), pois a proximidade facilita a interação das partes } \\
\text { envolvidas e a execução do projeto como um todo. O contato inicial é } \\
\text { geralmente estabelecido entre o líder de projeto da empresa ou o } \\
\text { executivo principal com um cientista conhecido da instituição. A escolha } \\
\text { do parceiro acadêmico por parte da empresa é baseada inicialmente no } \\
\text { contato pessoal precedente e nas interações anteriores, se existirem, ou } \\
\text { em recomendações pessoais. }\end{array}$ \\
\hline
\end{tabular}

Continua 
Tabela 1 (continuação)

\begin{tabular}{|c|c|c|}
\hline \multicolumn{3}{|c|}{ ETAPA INICIAL DOS PROJETOS COOPERATIVOS } \\
\hline Subetapas & Procedimentos & Descrição \\
\hline $\begin{array}{l}\text { Considerações } \\
\text { antecedentes } \\
\text { do projeto da } \\
\text { instituição da }\end{array}$ & $\frac{\text { Nível de }}{\underline{\text { importância }}} \underset{\text { para a }}{\text { universidade }}$ & $\begin{array}{l}\text { O projeto deverá ter importância estratégica para a instituição acadêmica, } \\
\text { de forma a incrementar a estruturação de linhas de pesquisa que, no } \\
\text { futuro, terão grande relevância tecnológica e comercial. }\end{array}$ \\
\hline
\end{tabular}
tecnologia

Considerações e aceitação do projeto

Contrato do projeto e estruturação da execução

\section{Especificaçõos} $\underline{\text { da estruturação }}$
A instituição selecionada para compartilhar o desenvolvimento dos projetos pode ser universidade, instituição de pesquisa do governo, fundação de pesquisa ou associação de pesquisa da indústria. $\mathrm{O}$ cientista aceita a parceria por uma variedade de razões. As recomendações pessoais e as obrigações amigáveis são importantes para empresa, mas a aceitação efetiva surge do interesse e do entusiasmo gerados pela natureza inovadora do projeto. O projeto é visto como espaço para aprender, captar recursos adicionais, gerar tecnologias e ter maior participação no segmento empresarial.

O contrato do projeto requer que a empresa desenvolva conjuntamente uma inovação com uma instituição de pesquisa e para tal utilizar-se-ão habilidades, conhecimentos e recursos de ambas as partes. O projeto resulta eventualmente na criação comum de nova tecnologia. O contrato entre as duas organizações é geralmente flexível, permitindo expansões e mudanças, isso porque o conhecimento criado durante o projeto conduz a novas linhas tecnológicas. A estrutura do contrato e a execução do projeto se tornam viáveis, se ambos os parceiros tiverem equipamentos, infra-estrutura e habilidades claramente complementares que não podem ser adquiridos individualmente.

Nota. Fonte: Conceitos obtidos em fontes diversas, como Bonaccorsi e Piccaluga (1994), Prabhú, (1999), Mora-Valentin (2000), Schartinger et al. (2002), Barnes et al. (2002), Siegel et al. (2003), Mora-Valentin et al. (2004), Laursena e Salterb (2004) e Debackere e Veugelers (2005).

Tabela 2

Etapa de Execução dos Projetos Cooperativos

ETAPA DE EXECUÇÃO DOS PROJETOS COOPERATIVOS

\begin{tabular}{|c|c|c|}
\hline Subetapas & Procedimentos & Descrição \\
\hline \multirow[t]{2}{*}{$\begin{array}{l}\text { Processo de } \\
\text { execução do } \\
\text { projeto comum }\end{array}$} & $\begin{array}{l}\text { Trabalho } \\
\text { cooperativo }\end{array}$ & $\begin{array}{l}\text { O trabalho envolve o desenvolvimento de inovações para aplicações } \\
\text { imediatas e futuras. Um coordenador é designado para administrar a } \\
\text { interface empresa-universidade e ocorrem diversas reuniões durante } \\
\text { todo o projeto para coordenar as atividades. Há também interação } \\
\text { próxima e freqüente entre a instituição acadêmica e as equipes da } \\
\text { empresa. }\end{array}$ \\
\hline & $\frac{\text { Expansão do }}{\frac{\text { espaço do }}{\text { projeto }}}$ & $\begin{array}{l}\text { O escopo do projeto se expande normalmente, quando o processo de } \\
\text { interação gera novos conhecimentos e novas linhas de pesquisa. A } \\
\text { empresa estará disposta a explorar essas novas linhas, se existir } \\
\text { adequada disponibilidade de capital, habilidades e tempo e se o } \\
\text { risco do investimento for aceitável. A escolha da empresa de } \\
\text { explorar tais linhas também está baseada na facilidade de interação } \\
\text { com a instituição acadêmica, no desenvolvimento dos } \\
\text { relacionamentos interpessoais, nos resultados do projeto até o } \\
\text { presente estágio e na natureza das linhas tecnológicas emergentes. }\end{array}$ \\
\hline
\end{tabular}


Tabela 2 (continuação)

\begin{tabular}{|c|c|c|}
\hline \multicolumn{3}{|c|}{ ETAPA DE EXECUÇÃO DOS PROJETOS COOPERATIVOS } \\
\hline Subetapas & Procedimentos & Descrição \\
\hline \multirow[t]{3}{*}{$\begin{array}{l}\text { Processo de } \\
\text { execução do } \\
\text { projeto comum }\end{array}$} & $\frac{\text { Nível do }}{\underline{\text { interesse }}}$ & $\begin{array}{l}\text { O projeto é caracterizado pelo elevado interesse pessoal e } \\
\text { organizacional da empresa e da instituição acadêmica. Há um grau } \\
\text { elevado de interesse e de iniciativa por parte dos executivos líderes } \\
\text { ou da equipe de projetos para iniciar, conduzir e controlar } \\
\text { ativamente as atividades. Os participantes também ficam altamente } \\
\text { entusiasmados, porque encaram o mesmo como oportunidade para } \\
\text { aprender habilidades novas. }\end{array}$ \\
\hline & $\frac{\frac{\text { Relacionamento }}{\text { da instituição de }}}{\frac{\text { pesquisa com a }}{\text { empresa }}}$ & $\begin{array}{l}\text { O relacionamento empresa-universidade é primeiramente relacional } \\
\text { e há pouca extensão contratual. Com o desenvolvimento do } \\
\text { relacionamento interpessoal entre as partes envolvidas, os níveis de } \\
\text { confiança e de entusiasmo associados ao projeto se expandem, e os } \\
\text { primeiros acordos formais são efetivados. Com o desenvolvimento } \\
\text { dos projetos, os parceiros acabam dedicando esforços expressivos à } \\
\text { sua execução, extrapolando as especificações de comprometimento } \\
\text { detalhadas formalmente no contrato. }\end{array}$ \\
\hline & $\frac{\text { Problemas e sua }}{\underline{\text { definição }}}$ & $\begin{array}{l}\text { Os problemas estão relacionados geralmente à ambigüidade inicial } \\
\text { na definição do projeto e em seu tempo excedente de mudança. } \\
\text { Também ocorrem pela ausência de uma comunicação efetiva. }\end{array}$ \\
\hline \multirow[t]{3}{*}{$\begin{array}{l}\text { Processo de } \\
\text { aprendizagem do } \\
\text { projeto comum }\end{array}$} & $\frac{\frac{\text { Processo de }}{\text { aprendizagem }}}{\frac{\text { dentro da }}{\text { instituição }}}$ & $\begin{array}{l}\text { A aprendizagem dentro da instituição acadêmica ocorre quando há } \\
\text { interação elevada entre os cientistas e os membros da empresa. } \\
\text { Dessa forma, aprende-se individualmente com a experiência da } \\
\text { criação da nova tecnologia e aprende-se também com a exposição à } \\
\text { prática industrial. O maior convívio com o segmento empresarial } \\
\text { garante que os cientistas tenham acesso aos problemas práticos e } \\
\text { teóricos e esses poderão fomentar as pesquisas futuras. }\end{array}$ \\
\hline & $\frac{\frac{\text { Processo de }}{\text { aprendizagem }}}{\frac{\text { dentro da }}{\text { empresa }}}$ & $\begin{array}{l}\text { A aprendizagem dentro da empresa também ocorre quando há } \\
\text { interação elevada entre os cientistas e a equipe interna de projetos. } \\
\text { Dessa forma, aprende-se individualmente com a experiência da } \\
\text { criação da nova tecnologia e aprende-se também com a exposição à } \\
\text { literatura técnica do campo de atuação da empresa. }\end{array}$ \\
\hline & $\begin{array}{l}\frac{\text { Processo de }}{\text { aprendizagem }} \\
\underline{\text { comum }}\end{array}$ & $\begin{array}{l}\text { Ocorre quando o conhecimento complementar é disseminado entre as } \\
\text { partes envolvidas, e o novo conhecimento é criado conjuntamente. A } \\
\text { aprendizagem é igual para a empresa e para a universidade, pois o } \\
\text { projeto resulta no desenvolvimento de potencialidades que serão } \\
\text { incorporadas por ambas as instituições. }\end{array}$ \\
\hline
\end{tabular}

Nota. Fonte: Conceitos obtidos em fontes diversas, como Bonaccorsi e Piccaluga (1994), Prabhú, (1999), Mora-Valentin (2000), Schartinger et al. (2002), Barnes et al. (2002), Siegel et al. (2003), Mora-Valentin et al. (2004), Laursena e Salterb (2004) e Debackere e Veugelers (2005). 
Tabela 3

\section{Etapa de Finalização dos Projetos Cooperativos}

\begin{tabular}{|c|c|c|}
\hline \multicolumn{3}{|c|}{ ETAPA DE FINALIZAÇÃO DOS PROJETOS COOPERATIVOS } \\
\hline Subetapas & Procedimentos & Descrição \\
\hline $\begin{array}{c}\text { Avaliações do } \\
\text { projeto }\end{array}$ & $\begin{array}{c}\text { Mecanismos de } \\
\text { avaliação }\end{array}$ & $\begin{array}{l}\text { A avaliação da instituição acadêmica por parte da empresa é norteada } \\
\text { pelos seguintes aspectos: a base de conhecimento dos membros } \\
\text { acadêmicos que participaram do projeto; a qualidade e a facilidade da } \\
\text { interação com eles; a habilidade da instituição em compreender a } \\
\text { complexidade do problema tecnológico enfrentado pela empresa; a sua } \\
\text { habilidade em desenvolver uma tecnologia nova que atenda às } \\
\text { exigências especiais da empresa; e a sua eficácia ao executar o projeto. } \\
\text { A empresa terá uma visão positiva da cooperação tecnológica, se esses } \\
\text { aspectos foram avaliados também de forma positiva. Similarmente, a } \\
\text { avaliação da empresa por parte da instituição acadêmica é } \\
\text { fundamentada pela: clareza demonstrada pela empresa ao comunicar } \\
\text { suas exigências e expectativas; o interesse da mesma no projeto, a sua } \\
\text { contribuição para o desenvolvimento da nova tecnologia; a sua } \\
\text { compreensão em aceitar possíveis falhas; e a facilidade de interação } \\
\text { com os membros da empresa. A instituição acadêmica terá uma visão } \\
\text { positiva da cooperação tecnológica, se esses aspectos foram avaliados } \\
\text { de forma positiva. }\end{array}$ \\
\hline
\end{tabular}

$\begin{gathered}\text { Conseqüências } \\ \text { do projeto }\end{gathered}$
$\frac{\underline{\text { Outros }}}{\text { resultados do }}$
$\underline{\text { projeto }}$

$\underline{\text { Benefícios }}$

Expectativas de cooperação futura
O resultado mais expressivo tanto para a instituição de pesquisa quanto para a empresa é o salto tecnológico que conduz a novas maneiras de pensar e de resolver problemas. $\mathrm{Na}$ instituição acadêmica o salto tecnológico resulta da emergência e da posterior exploração de novas linhas de pesquisa. Enquanto o conhecimento novo é absorvido, ocorre a seleção de novas linhas de pesquisa, cuja exploração dependerá da disponibilidade de tempo e de recursos. Similarmente, enquanto o conhecimento novo é absorvido, a empresa identifica problemas tecnológicos e seleciona produtos e processo que precisam ser inovados. Se os recursos (tempo, capital e equipamentos) requeridos para a exploração dessas questões não estiverem disponíveis, elas serão trabalhadas no futuro. Os resultados positivos dos projetos são que eles incentivam as instituições a explorarem juntas as novas oportunidades colaborativas.

Freqüentemente novas fronteiras tecnológicas são abertas. Isto pode gerar transbordamentos tecnológicos no contexto interno das empresas, ou seja, as novas tecnologias podem extrapolar os limites do espaço do projeto. A interação com uma instituição acadêmica expõe também a empresa a uma literatura técnica robusta sobre o seu campo de atuação. Isso pode impulsionar mudanças tecnológicas em áreas que não estão inteiramente relacionadas ao projeto. Pode também haver um avanço tecnológico total enquanto as inovações, os conhecimentos e as habilidades advindos do projeto são difundidos dentro da empresa. A instituição acadêmica também pode lograr todos estes benefícios.

Se as avaliações do projeto forem positivas nas duas instituições, então a interação tem maior propensão a continuar. Neste caso a empresa fica geralmente disposta a trabalhar com a instituição acadêmica em projetos colaborativos subseqüentes, e a instituição acadêmica aceita participar de tais projetos se tiver conhecimentos e habilidades que poderão complementá-lo.

Nota. Fonte: Conceitos obtidos em fontes diversas, como Bonaccorsi e Piccaluga (1994), Prabhú, (1999), Mora-Valentin (2000), Schartinger et al. (2002), Barnes et al. (2002), Siegel et al. (2003), Mora-Valentin et al. (2004), Laursena e Salterb (2004) e Debackere e Veugelers (2005). 
A descrição detalhada dessas etapas contribui para a compreensão gerencial das parcerias tecnológicas estabelecidas entre empresas e universidades/institutos de pesquisa, o que facilita a compreensão das múltiplas combinações dos níveis individual, organizacional e interorganizacional e o impacto que eles exercem sobre as etapas da cooperação empresa-universidade. Pode também fornecer introspecções práticas para empresas, instituições acadêmicas e entidades governamentais no que tange à viabilização tecnológica e comercial da cooperação empresa-universidade.

Diante dessas discussões teóricas sobre inovação e cooperação tecnológica, pode-se inferir que a questão norteadora da inovação não é mais o que está disponível cientificamente?, mas o que é necessário tecnologicamente?, ou seja, o processo de inovação deve ser guiado pela associação das descobertas científicas com as necessidades tecnológicas. Dessa forma, deve-se administrar o processo inovador por meio de uma gestão criativa, aberta e flexível que aproveita os conhecimentos científicos novos e antigos, considera as oportunidades dos mercados nacionais e internacionais, observa as necessidades dos clientes locais e estrangeiros, avalia setores correlatos em busca de tecnologias complementares, estabelece parcerias tecnológicas globais para compartilhar habilidades e dividir custos e riscos e, por fim, gera de forma competente inovações não só de produtos e processos, mas inovações organizacionais e mercadológicas.

Pode-se concluir, também, que são diversos os arranjos e mecanismos de gestão da cooperação tecnológica. No entanto não existe consenso ou padrão rígido para a utilização de determinados arranjos, mecanismos e procedimentos gerenciais, já que cada situação de cooperação poderá ser extremamente diferente de outras experiências anteriores, não devendo a empresa ou universidade/instituto de pesquisa buscar repetir exatamente os procedimentos já adotados. Sendo uma relação que envolve grupos distintos de pessoas, vindos de condições diversas e pesquisando coisas novas, naturalmente o processo exigirá cada vez mais novos instrumentos e estilos alternativos de trabalho. A escolha de determinados arranjos e mecanismos gerenciais dependerá da posição e dos objetivos de cada participante em face do processo e deverá contemplar a maleabilidade e adequações necessárias ao tipo de relação a ser desenvolvida.

\section{Metodologia de Pesquisa}

A pesquisa foi qualitativa e assumiu natureza descritiva. Segundo Richardson (1999), a pesquisa qualitativa é caracterizada como tentativa de compreensão detalhada dos significados e das características situacionais apresentadas pelos entrevistados, em lugar de produção de medidas quantitativas de características ou comportamentos. Com relação à pesquisa descritiva, Gil (2002) argumenta que o seu objetivo primordial é a descrição das características de determinada população ou fenômeno ou, então, o estabelecimento de relações entre variáveis.

O método utilizado na pesquisa foi o estudo de caso, uma vez que o estudo intensivo de um caso permite a avaliação profunda, exaustiva e comparativa de um ou poucos objetos (Gil, 2002).

A escolha da empresa estudada foi definida de acordo com quatro critérios: $1^{\circ}$ a empresa deveria realizar atividades industriais de extração ou de transformação; $2^{\circ}$ deveria ser brasileira ou possuir um histórico brasileiro expressivo (empresa com histórico brasileiro superior a 15 anos); $3^{\circ}$ ter unidades produtivas no exterior; e $4^{\circ}$ teria de possuir parcerias tecnológicas com fontes externas de tecnologia, tais como universidades e institutos de pesquisa nacionais e/ou internacionais. A categorização das atividades industriais (extração e transformação) foi efetuada a partir da Classificação Nacional de Atividade Econômica [CNAE] (Instituto Brasileiro de Geografia e Estatística [IBGE], 2007).

A partir dos critérios listados, selecionou-se a Empresa Brasileira de Compressores [Embraco]. Cabe ressaltar que a empresa selecionada não possui atualmente controle acionário brasileiro, pois, em 1997, a americana Whirpool passou a controlá-la. No entanto o estudo de caso da Embraco foi mantido devido ao seu expressivo histórico brasileiro $(20$ anos $)$ e também porque as atividades de cooperação e de internacionalização foram iniciadas e solidificadas antes da sua aquisição. Deve-se, 
ainda, mencionar que a empresa continua a operar de forma estruturalmente independente em virtude da peculiaridade de seu negócio, tendo, portanto, uma gestão nacional autônoma (Empresa Brasileira de Compressores [Embraco], 2007).

Foram utilizados nesta pesquisa dados primários e secundários. Os primários foram coletados por meio de entrevistas semi-estruturadas (realizadas com o coordenador geral de P\&D e com dois gerentes responsáveis pela cooperação empresa-universidade) e de um questionário (aplicado no nível gerencial do departamento de $\mathrm{P} \& \mathrm{D})$. Os secundários foram obtidos em relatórios e documentos organizacionais e também em fontes secundárias de evidência, como jornais, periódicos, anais de congresso e no site da empresa.

Para Martins (2006), são denominados secundários os dados já coletados que se encontram organizados em arquivos, banco de dados e anuários estatísticos, relatórios etc. Em contraste, os dados primários são aqueles colhidos diretamente na fonte.

Segundo Gil (2002), a entrevista, enquanto técnica de coleta de dados, é bastante adequada para a obtenção de informações sobre o que as pessoas sabem, crêem, esperam, sentem ou desejam, pretendem fazer, fazem ou fizeram, bem como acerca de suas explicações ou razões a respeito dos fatos precedentes. $\mathrm{O}$ autor também afirma que, em virtude da sua flexibilidade, a entrevista é umas das técnicas mais utilizadas no âmbito das ciências sociais.

É importante esclarecer que a coleta de dados foi efetivada por duas etapas seqüenciais. A primeira etapa envolveu uma coleta prévia de dados primários e secundários, ou seja, foi enviado à Embraco um questionário com questões abertas para se obterem informações gerais sobre a cooperação empresa-universidade. Elaborou-se, também, nessa primeira, etapa um dossiê da empresa, a partir de dados secundários obtidos em jornais, periódicos, anais de congresso e no site da empresa. Depois que essas atividades foram concluídas, iniciou-se a segunda etapa, e dados primários e secundários foram coletados, respectivamente, nas entrevistas e nos documentos e relatórios fornecidos pela empresa (cópias dos relatórios dos projetos cooperativos e dos contratos de cooperação).

Para interpretar os dados, utilizou-se a análise documental e de conteúdo. Freitas e Janissek (2000) argumentam que a técnica de análise de conteúdo permite o aprofundamento no mundo dos significados das ações e relações humanas, dado pouco perceptível ou captável pelos métodos quantitativos. A análise de conteúdo, segundo os autores, permite ir além do que se tem como resultado claro e manifesto; podese obter por inferência, até mesmo aquilo que o autor deixou subentendido.

Para orientar a replicação do estudo, é apresentado a seguir um protocolo de pesquisa.

Tabela 4

Protocolo de Pesquisa

\section{PROTOCOLO DE PESQUISA}

$\begin{array}{cl}\begin{array}{c}\text { Etapas } \\ \text { da }\end{array} & \begin{array}{l}\text { 1. Levantamento bibliográfico: realizou-se um levantamento bibliográfico sobre as temáticas } \\ \text { pesquisa }\end{array} \\ \text { inovação e cooperação empresa-universidade. } & \text { 2. Definição dos casos: a partir de quatro critérios selecionou-se a Embraco como caso a ser } \\ & \text { estudado em profundidade. } \\ & \text { 3. } \text { Aprimoramento da metodologia: detalhamento da metodologia e incorporação de instrumentos } \\ \text { de pesquisa que viabilizaram a coleta e a interpretação dos dados. } \\ \text { 4. Primeira etapa de coleta de dados: foram enviados aos gerentes de P\&D da matriz da Embraco } \\ \text { questionários para obter informações gerais sobre cooperação empresa universidade, além disso, } \\ \text { elaborou-se um dossiê da empresa a partir de dados secundários. } \\ \text { 5. Segunda etapa de coleta de dados: foram realizadas entrevistas na matriz da Embraco e dados } \\ \text { secundários foram obtidos em documentos e relatórios organizacionais. } \\ \text { 6. Análise do caso: análise qualitativa do caso e reflexão crítica entre prática e teoria. }\end{array}$




\section{Tabela 4 (continuação)}

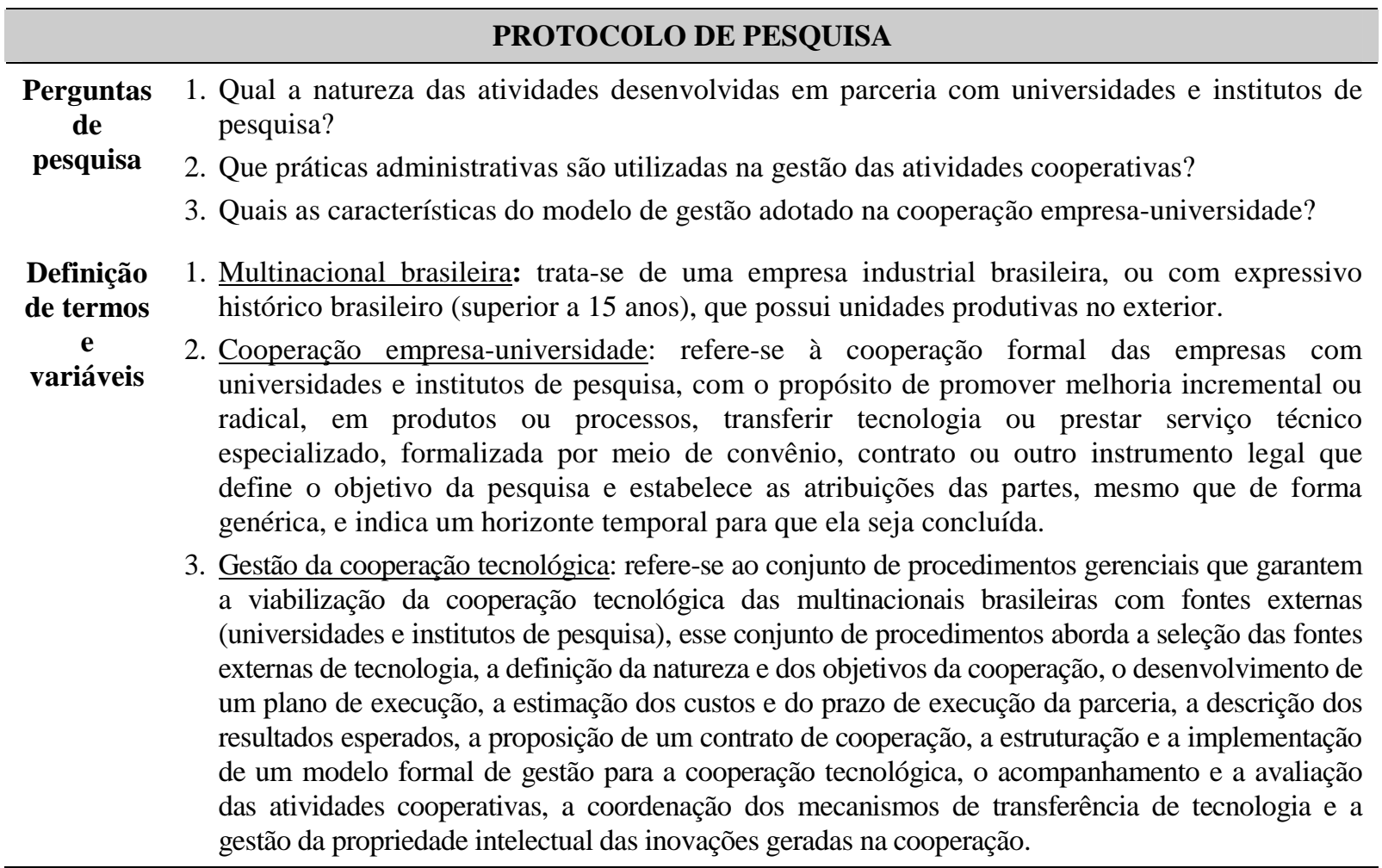

Nota. Fonte: Elaborada pelos autores.

\section{Resultados dA Pesquisa}

\section{Histórico da Empresa}

Fundada em 1971, a Embraco começou a produzir com o objetivo inicial de suprir as necessidades da indústria brasileira, e já em 1977, são iniciadas atividades de exportação para a América Latina. Em 1981, inicia-se o desenvolvimento de tecnologia própria em parceria com universidades e centros de pesquisa e, nos primeiros anos de 1990, a empresa deu início ao processo de abertura de bases produtivas fora do Brasil e a conseqüiente ampliação de sua estrutura global de vendas.

Atualmente a empresa possui três unidades produtivas no exterior e emprega cerca de 10.416 colaboradores: 6.147 no Brasil, 54 nos EUA, 908 na Itália, 2.100 na Eslováquia e 1.207 na China. Estima-se que o seu market share mundial seja de $20 \%$ cuja distribuição assume a seguinte ordenação: 47\% da América do Sul, 45\% da América do Norte, 15\% da Europa e 6\% da Ásia. O único mercado que se prevê crescimento nos próximos anos é o asiático. A competição na China tem recebido especial atenção nos últimos anos, e a empresa reconhece esse país como ambiente de alta competitividade, diversidade e potencialidade.

\section{Natureza das Atividades Cooperativas}

A Embraco possui 25 anos de história de cooperação tecnológica com instituições nacionais e internacionais. O primeiro caso de cooperação tecnológica ocorreu em 1981; de acordo com um executivo da empresa, "os motivadores centrais para o estabelecimento da parceria foram a não disponibilidade interna de conhecimentos e habilidades que promovessem o incremento de produtos e 
processos e a necessidade de atenuar a dependência tecnológica até então mantida com determinados concorrentes e fornecedores".

Com relação à natureza das parcerias que a empresa estabelece atualmente com universidades e institutos de pesquisa, nota-se que elas estão associadas a atividades de pesquisa, desenvolvimento e monitoramento tecnológico. Os projetos de monitoramento possuem baixa maturidade e atratividade; neste caso, as instituições parceiras acompanham a evolução de algumas temáticas científicas que futuramente poderão ser atrativas. Os projetos de pesquisa apresentam elevada atratividade e baixa maturidade, envolvem intensas atividades de pesquisa e procuram gerar novos conhecimentos em acústica e vibração, máquinas e motores, trocas de calor, gestão de $\mathrm{P} \& \mathrm{D}$ e novas tecnologias em refrigeração. Já os projetos de desenvolvimento tecnológico possuem elevada maturidade e atratividade, abordam atividades tanto de pesquisa quanto de desenvolvimento e procuram transformar os conhecimentos gerados nos projetos de pesquisa em conceitos de novos produtos, processos e/ou componentes.

Para que esses projetos cooperativos se efetivem, a empresa recorre aos seguintes mecanismos.

a) Consórcios: a empresa participa ativamente de consórcios de pesquisa conjuntamente com outras companhias, com o objetivo de acessar conhecimento no estado da arte em alguns campos especializados e de monitorar o movimento dos clientes e concorrentes. Os consórcios são utilizados como fontes de inovação e de informação para as pesquisas pré-competitivas realizadas pela empresa. Para participar desses consórcios, a empresa paga uma taxa anual à instituição gestora. O acompanhamento deste tipo de parceria ocorre pela avaliação periódica de relatórios de atividades e por meio de reuniões. Sempre que possível, a empresa busca o contato direto com os estudantes e os professores envolvidos diretamente no consórcio.

b) Cooperação com universidades e companhias de outros segmentos de mercado: este tipo de parceria é realizado com o objetivo de alcançar resultados mais rápidos mediante a sinergia das competências que são compartilhadas entre as instituições parceiras e também pela possibilidade de compartilhar custos. Os objetivos e as expectativas são planejados de forma colaborativa, e os recursos financeiros provêm das instituições envolvidas. O acompanhamento é efetivado pela execução de reuniões periódicas.

c) Projetos pontuais: esta parceria ocorre quando falta conhecimento em uma área de interesse específica e há necessidade de resultados imediatos que serão prontamente incorporados pela empresa. Os projetos pontuais exigem investimentos expressivos por parte da empresa. $\mathrm{O}$ acompanhamento é efetivado pela execução de reuniões periódicas.

d) Programas de pesquisa: são parcerias de longo prazo que continuamente geram conhecimentos que sustentam as competências centrais da empresa. Além disso, constituem expressivo reservatório de novos talentos que continuamente são absorvidos pela empresa. Os programas de pesquisa são as principais fontes de conhecimento e de informação para o desenvolvimento dos projetos tecnológicos da empresa. Os recursos financeiros utilizados para sustentar estes programas são obtidos de linhas de financiamento para pesquisas cooperativas, sendo os principais agentes de fomento o Conselho Nacional de Desenvolvimento Científico e Tecnológico [CNPq], a Financiadora de Estudos e Projetos [FINEP], e a Coordenação de Aperfeiçoamento de Pessoal de Nível Superior [CAPES]. O acompanhamento deste tipo de parceria ocorre pela avaliação periódica de relatórios de atividades e por meio de reuniões. A empresa busca continuamente o contato direto com os estudantes e professores envolvidos diretamente nos programas de pesquisa. Para tal fim nomeia colaboradores da área de $P \& D$ e estes são responsáveis pela gestão da interface empresa-universidade.

Os consórcios normalmente duram de 1 a 2 anos, a cooperação com universidades e companhias de outros segmentos de mercado é finalizada após o segundo ano de parceria; projetos pontuais duram em média 12 meses; e os programas de pesquisa são de longo prazo, normalmente referem-se a parcerias tecnológicas fixas e contínuas. Atualmente a empresa possui aproximadamente 80 projetos 
cooperativos, 20 são projetos de baixo impacto científico e representam os projetos pontuais que são realizados para suprir necessidades específicas; 20 são projetos de relevância científica mediana, focados em pesquisas pré-competitivas que estão associadas aos consórcios e às parcerias com universidades e companhias de outros segmentos de mercado; e os 60 restantes referem-se a projetos com impacto científico expressivo que se inserem nos programas de pesquisa, tais como os projetos de desenvolvimento tecnológico.

A decisão de estabelecer parcerias com universidades e institutos de pesquisa é centralizada na unidade de Joinville/Brasil (matriz), nota-se ainda que as parcerias vinculadas a essa unidade são mais intensas e freqüentes, estando associadas a programas de pesquisa e a consórcios com instituições tanto nacionais quanto internacionais; já as subsidiárias da empresa realizam apenas projetos pontuais com parceiros internacionais. Outro ponto relevante é que tanto a matriz quanto as subsidiárias da empresa possuem autonomia para gerenciar as suas parcerias; e há um monitoramento parcial, por parte da matriz, das parcerias que estão vinculadas às subsidiárias.

É importante ressaltar que os conhecimentos gerados nas parcerias tecnológicas são absorvidos pela empresa e, posteriormente, materializados em novos produtos, processos e/ou componentes, garantindo a liderança da empresa em algumas tecnologias ainda não dominadas pelos concorrentes. Quando as tecnologias são efetivamente dominadas pelos concorrentes, a empresa descentraliza as atividades de desenvolvimento e customização para as suas subsidiárias (unidades estrangeiras); no caso de tecnologias não dominadas, toda e qualquer atividade de $P \& D$ é centralizada na unidade de Joinville-BR (matriz), pois a empresa acredita que este procedimento de centralização implica custos menores de coordenação e garante a formação de uma massa crítica diferenciada.

De acordo com um dos executivos da empresa, "as parcerias tecnológicas são atualmente os pilares de sustentação das atividades internas de P\&D; elas reforçam a posição de liderança tecnológica da empresa. Os projetos cooperativos estão ligados à competência central da empresa, e os conhecimentos gerados nas parcerias tecnológicas são essenciais ao desenvolvimento tecnológico dos produtos e dos processos da empresa. Assim, verifica-se que a cooperação com fontes externas de tecnologia (universidades e institutos de pesquisa) não só sustenta a competitividade tecnológica da empresa, mas também garante que ela seja renovada de forma criativa".

\section{Práticas Administrativas Adotadas na Cooperação}

As práticas administrativas adotadas pela Embraco na cooperação empresa-universidade são as seguintes.

\section{a) Definição do portfólio de projetos cooperativos}

Para definir o portfólio de projetos cooperativos, a empresa leva em consideração as metas formuladas no seu planejamento tecnológico e o estado corrente dos conhecimentos acadêmicos, das inovações tecnológicas do mercado, das necessidades da sociedade e dos desejos dos clientes. Levantadas as tendências científicas, tecnológicas e mercadológicas, a empresa formula os seus projetos preliminares de $\mathrm{P} \& \mathrm{D}$ e aqueles que são considerados estratégicos e que exigem conhecimentos e competências que não estão disponíveis internamente; são, então, desenvolvidos em parcerias com universidades e institutos de pesquisa. Segundo um executivo da empresa, "os projetos cooperativos estão vinculados às competências centrais da empresa". É importante frisar que os projetos cooperativos são agrupados em um portfólio específico, que é subdividido em atividades de pesquisa, de desenvolvimento e de monitoramento tecnológico. Depois que os projetos cooperativos foram definidos, a empresa inicia a fase de seleção dos parceiros tecnológicos.

Deve-se também ressaltar que na definição do portfólio de projetos cooperativos não há envolvimento direto dos parceiros tecnológicos; as suas necessidades não são consideradas formalmente nesta fase gerencial. 


\section{b) Seleção dos parceiros tecnológicos}

Inicialmente a empresa procura desenvolver os projetos cooperativos com as instituições que já são parceiras. Novas parcerias são buscadas, quando as atuais não oferecem as habilidades e as competências necessárias à execução de um determinado projeto. Nesse caso, são requeridas indicações das instituições parceiras sobre novos parceiros tecnológicos; paralelamente, é realizado um mapeamento por parte da empresa dos reservatórios nacionais e internacionais de conhecimento e de tecnologia que são atrativos para o segmento de atuação da empresa; para tal são levados em consideração os seguintes critérios: as habilidades e as competências científicas e de gestão dos potenciais parceiros e a proximidade geográfica. Levando-se em conta esses critérios e considerandose a indicação dos seus parceiros tecnológicos, a empresa lista as potenciais instituições parceiras e realiza um programa de visita a elas para conhecer as suas competências, habilidades, estruturas, recursos e identificar o seu real desempenho.

Realizadas as visitas, a empresa finalmente opta por uma instituição e começa a estabelecer as primeiras negociações com ela. Se o contato inicial é satisfatório, a empresa dá continuidade aos trabalhos cooperativos, sendo o próximo passo o planejamento da parceria; caso seja insatisfatório, a empresa recorre à sua segunda opção. Este procedimento ocorrerá sucessivamente até que a instituição parceira demonstre real interesse em cooperar, pois a empresa acredita que não basta ter competências, habilidades e recursos para se realizarem atividades cooperativas, é também relevante que ambos os parceiros tenham real interesse nos projetos cooperativos.

Quando a empresa tem a opção de desenvolver projetos com instituições que já são parceiras, são adotados os seguintes critérios para selecionar o parceiro tecnológico: as habilidades e as competências científicas e de gestão da instituição, os resultados das parcerias anteriormente realizadas e a proximidade geográfica com a empresa. Vencida essa etapa, a empresa classifica as instituições mais atrativas e, posteriormente, estabelece um primeiro contato para avaliar o interesse da instituição listada em primeiro lugar. Se o contato inicial é satisfatório e as habilidades e competências da empresa e da instituição se complementarem mutuamente, a empresa dá continuidade aos trabalhos cooperativos, sendo o próximo passo o planejamento da parceria.

É importante ressaltar que, antes da seleção dos parceiros tecnológicos, a empresa normalmente já possui um pré-projeto de cooperação, com escopo já definido; portanto o parceiro a ser selecionado deverá ter, basicamente, interesse e competência para executar cooperativamente o referido projeto. As opções de parceiros poderiam ampliar-se, se a empresa assumisse uma postura expansiva e participativa quanto ao estabelecimento prévio do pré-projeto cooperativo, pois parceiros portadores de futuro podem ser desconsiderados e/ou descartados, porque não demonstraram interesse ou não detinham competências para a realização de um determinado projeto com escopo já definido pela empresa.

Como alternativas, recomenda-se que a seleção dos parceiros seja iniciada pela busca de instituições já parceiras ou não (universidades e institutos de pesquisa nacionais e internacionais), que atuam dentro das temáticas de $\mathrm{P} \& \mathrm{D}$ de interesse da empresa. Posteriormente, um pré-projeto de cooperação deveria ser construído de forma participativa, estando o seu escopo em sintonia com os interesses da empresa e do parceiro tecnológico.

\section{c) Planejamento da cooperação tecnológica}

O planejamento da parceria envolve a definição dos seguintes aspectos: a revisão do escopo do projeto cooperativo; as metas de curto, médio e longo prazos; os prazos de execução do projeto; os recursos necessários para viabilizar as atividades cooperativas e as fontes de fomento; a definição dos procedimentos gerenciais que serão utilizados no acompanhamento e controle do projeto; e a política de propriedade intelectual que fomentará as atividades cooperativas. Apesar desse planejamento formal, é importante ressaltar que a flexibilidade e a criatividade permeiam as atividades cooperativas, sendo comum nos projetos de cooperação tecnológica a ampliação de temáticas, a revisão de prazos e metas e o surgimento de novas linhas de pesquisa. Todas essas modificações são negociadas entre os 
atores envolvidos, para que as necessidades da empresa e os anseios da universidade não fiquem prejudicados.

Segundo um executivo da empresa, "a interface empresa-universidade é permeada não só por um planejamento formal, mas por práticas gerenciais flexíveis, que garantem a manutenção de um ambiente cooperativo criativo, que atende às necessidades das partes envolvidas e paralelamente gera conhecimentos que fomentarão, no futuro, as atividades tecnológicas da empresa e as atividades científicas da universidade".

Apesar de válido o esforço da empresa em instituir uma postura participativa na fase de planejamento da cooperação, é relevante reforçar novamente a necessidade de pensar também participativamente durante as fases de definição do portfólio de projetos cooperativos e na fase de seleção dos parceiros, pois só assim ciência e tecnologia poderão de fato caminhar juntas desde o início da cooperação empresa-universidade.

\section{d) Definição dos contratos cooperativos}

Para formalizar cooperação tecnológica, especificamente os projetos pontuais e os programas de pesquisa, a empresa estabelece contratos de exclusividade. Os contratos de cooperação só não são exclusivos, quando a empresa realiza consórcios e acordos de cooperação com universidades e companhias de outros segmentos de mercado. O processo de formalização dos contratos cooperativos é iniciado pela elaboração de um documento que relata a natureza e os prazos do projeto, as responsabilidades de ambas as partes e as práticas de propriedade intelectual a serem adotadas nas atividades cooperativas. Posteriormente este documento é formatado de acordo com as especificações legais de um contrato, em seguida este é avaliado por ambas as partes. Caso não haja ressalvas, o contrato é finalmente assinado pelas partes e reconhecido em cartório. Para viabilizar este processo de formalização, a empresa e a instituição parceira normalmente recebem apoio gerencial e legal de agências de inovação, de escritórios de patentes e de assessores jurídicos privados.

\section{e) Estruturação dos recursos financeiros e físicos}

A empresa acredita que, para viabilizar as parcerias tecnológicas, são utilizadas fontes nacionais de fomento, sendo os principais agentes financiadores a própria empresa, Ministério da Ciência e Tecnologia [MCT], FINEP e CAPES. Quanto aos recursos físicos, são utilizados laboratórios e instalações tanto da empresa quanto das universidades e dos institutos de pesquisa parceiros.

Cabe frisar que a empresa não recorre a fontes e/ou órgãos internacionais para fomentar suas atividades cooperativas; portanto, nota-se a necessidade de instituir uma postura mais agressiva quanto à prospecção global por fontes de fomento à cooperação, seja financeira, fiscal ou estrutural, que envolverá o mapeamento e a monitoração contínua de oportunidades internacionais que ofereçam qualquer tipo de suporte à cooperação empresa-universidade.

\section{f) Estruturação das equipes de trabalho vinculadas às parcerias}

Nota-se a presença expressiva de estudantes de graduação e de pós-graduação, professores, técnicos, engenheiros, funcionários administrativos e dos colaboradores da área de P\&D da empresa.

Cada área temática de interesse da empresa - acústica e vibração, máquinas, motores, trocas de calor, gestão de P\&D e novas tecnologias em refrigeração - possui um gerente correspondente que é responsável pela gestão dos projetos cooperativos que estão associados ao escopo da sua respectiva área temática, e suas atribuições envolvem o acompanhamento dos projetos cooperativos por meio de reuniões com os membros da instituição parceira - estudantes, professores, técnicos, engenheiros, funcionários administrativos - e com a diretoria da área de $\mathrm{P} \& \mathrm{D}$ da empresa e pelo contato direto com a rotina de trabalho dos projetos; e o controle dos projetos cooperativos por meio do acompanhamento dos cronogramas de atividades e pela avaliação de relatórios de desempenho.

De acordo com um executivo da empresa, "a gestão eficiente das atividades cooperativas é 
diretamente influenciada pela atuação dos gerentes de projetos cooperativos, pois eles são responsáveis não só pela administração ativa da interface empresa-universidade, mas também pela manutenção dos interesses das partes envolvidas".

\section{g) Execução dos projetos cooperativos}

As metas definidas na etapa de planejamento, que foram posteriormente formalizadas no contrato, são agora executadas. Caso seja necessário, são efetuadas mudanças ao longo do ciclo de vida do projeto. Durante a execução dos projetos, há interação freqüente da empresa com a academia; ocorre comunicação contínua entre as partes envolvidas, de modo que cada um saiba especificamente o que o outro está fazendo. As reuniões são intensas, geralmente de longa duração, caracterizadas por um grau elevado de discussões e aceitações equivalentes das falhas e do sucesso e, quando necessário, os cronogramas e as metas das atividades cooperativas são repensados.

Uma grande dificuldade citada por um executivo da empresa, durante a efetiva execução dos projetos cooperativos, é "conciliar os fluxos de trabalho vigentes na empresa e nos parceiros tecnológicos, uma vez que o senso de urgência destes atores é imensamente distinto. Outro ponto colocado é a dificuldade de seguir os prazos que foram definidos na etapa de planejamento". Uma sugestão para superar estas dificuldades é definir um cronograma bem estruturado na fase de planejamento, já prevendo a necessidade de prazos complementares. Além disso, as mudanças de escopo e as alterações de prazos deverão ser avaliadas com cautela, porquanto, além de prezar a flexibilidade e a criatividade, será necessário manter a eficiência e a eficácia do projeto.

Esta análise remete muito à concepção gerencial da atividade de cooperação por ambas as partes, ou seja, empresa e universidade terão de se beneficiar mutuamente e conceber a cooperação como atividade não só científica e/ou tecnológica, mas também gerencial, cujo sucesso está atrelado à gestão sistêmica de prazos, custos, objetivos, pessoas, informações, interesses, infra-estrutura física e financeira, risco etc.

\section{h) Acompanhamento das atividades cooperativas}

O acompanhamento das parcerias é realizado pelos gerentes de projetos cooperativos e é efetivado pela avaliação periódica dos relatórios das atividades cooperativas e, por meio de reuniões, sempre que possível, busca-se o contato direto com os estudantes, professores, técnicos, engenheiros, funcionários administrativos envolvidos na parceria. Os gerentes de projetos cooperativos periodicamente realizam uma reunião com a diretoria de P\&D da empresa para apresentar a evolução das parcerias tecnológicas e discutir os seus pontos fortes e fracos, e definir sugestões de melhoria.

\section{i) Avaliação das parcerias tecnológicas}

A avaliação dos projetos cooperativos é realizada de forma sistemática, ao longo do desenvolvimento do projeto e, para efetivar os procedimentos de avaliação, os gerentes de projetos observam se as metas e os prazos definidos na etapa de planejamento estão sendo cumpridos. Caso ocorram desvios e problemas, estes serão analisados pelo gerente de projetos juntamente com a diretoria da área de $\mathrm{P} \& \mathrm{D}$ da empresa e com os pesquisadores e os funcionários administrativos da instituição parceira e, posteriormente, eles definirão de forma participativa as medidas corretivas.

Um processo de avaliação mais criterioso é implementado pela empresa, quando os projetos cooperativos são finalizados, e para tal são avaliados os seguintes aspectos: a base de conhecimento dos membros acadêmicos que participaram do projeto; a qualidade e a facilidade da interação com eles; a habilidade da instituição em compreender as necessidades da empresa; a sua habilidade em gerar conhecimentos que atendam às exigências tecnológicas da empresa; sua eficácia ao executar o projeto, tal como o cumprimento das metas e dos prazos estabelecidos na etapa de planejamento; e a sua habilidade de negociação, ao longo das atividades cooperativas. A empresa terá uma visão positiva da cooperação tecnológica, se esses critérios forem avaliados também de forma positiva.

Cabe ressaltar que a avaliação das parcerias tecnológicas está basicamente associada puramente à 
análise do processo de cooperação, não estando vinculada à análise dos resultados propriamente ditos das parcerias, como os conhecimentos gerados, as patentes depositadas e/ou concedidas, os trabalhos científicos publicados, os alunos contratados pela empresa, a geração de novos projetos cooperativos e o contato com novos parceiros tecnológicos. Além disso, os resultados da avaliação das parcerias não são registrados formalmente; assim informações relevantes podem ser esquecidas com o tempo.

\section{j) Transferência de conhecimento}

Para efetivar a transferência de conhecimento da universidade para a empresa, utilizam-se os seguintes mecanismos: reuniões entre os gerentes de projetos, a diretoria de P\&D da empresa e estudantes, professores, técnicos, engenheiros e funcionários administrativos da instituição parceira; contratação de alunos envolvidos nas parcerias tecnológicas; treinamento direcionado aos colaborados da área de P\&D para que eles possam internalizar os conhecimentos gerados na universidade. Em muitos casos, estes treinamentos são ministrados pelos professores e alunos da instituição parceira e pelos gerentes de projetos da empresa que participam diretamente das atividades cooperativas.

\section{k) Garantia da propriedade intelectual}

Todas as inovações geradas de forma cooperativa são patenteadas, e a titularidade é em nome da empresa e da instituição parceira, sendo que não poderá haver licenciamento para os concorrentes da empresa. De acordo com um executivo da empresa, "o ato de patentear é visto como uma prática de proteção da propriedade intelectual; ele não é concebido como estratégia de recuperação do capital investido em $\mathrm{P} \& \mathrm{D}$, ou seja, a empresa patenteia as suas inovações não para licenciá-las e sim para assegurar a propriedade intelectual, fortalecer a sua imagem inovadora e por ser uma prática comum entre os seus concorrentes".

Até que os projetos cooperativos gerem patentes, a empresa enfrenta dificuldades em estabelecer um equilíbrio entre o que deverá ser mantido em sigilo e o que poderá tornar-se público. Isso ocorre porque o desempenho dos pesquisadores universitários é basicamente avaliado pelo número de publicações, havendo, portanto, grande pressão por parte destes profissionais no que tange à divulgação dos resultados dos projetos cooperativos. Outra questão que agrava essa situação é que as atividades vinculadas à cooperação empresa-universidade ainda não são valorizadas adequadamente no âmbito acadêmico.

Fica evidente que reformas precisam ser realizadas quanto à estrutura de avaliação dos professores universitários, pois já é fato que alguns professores universitários possuem um perfil mais acadêmico, voltado à docência e à pesquisa puramente básica, sem qualquer aplicação prática; no entanto, há professores mais empreendedores, cujas pesquisas estão atreladas a problemas práticos. Como a existência desses perfis é uma realidade, devem-se criar condições de trabalho que garantam a coexistência de ambos, pois a revitalização do sistema brasileiro de inovação dependerá da atuação conjunta de professores acadêmicos e empreendedores.

\section{Modelo de Gestão da Cooperação}

O modelo de gestão adotado pela Embraco (matriz e subsidiárias) na cooperação empresauniversidade é formado por onze práticas administrativas que são efetivadas seqüencialmente, assumindo a configuração de um fluxo linear. Apenas as práticas de acompanhamento e de avaliação tendem a ocorrer de forma mais dinâmica, ao longo do processo de cooperação.

As práticas administrativas que integram o modelo de gestão da cooperação estão distribuídas em três fases.

1) Fase de pré-desenvolvimento da cooperação: definição do portfólio de projetos cooperativos, a seleção dos parceiros tecnológicos e planejamento da cooperação tecnológica.

2) Fase de desenvolvimento da cooperação: definição dos contratos cooperativos, estruturação dos 
recursos financeiros e físicos, estruturação das equipes de trabalho vinculadas às parcerias, execução dos projetos cooperativos e acompanhamento das atividades cooperativas.

3) Fase de pós-desenvolvimento da cooperação: avaliação das parcerias tecnológicas, transferência de conhecimento e garantia da propriedade intelectual.

A seguir, é apresentado um quadro que detalha o modelo de gestão adotado pela Embraco, na administração da cooperação empresa-universidade.

Tabela 5

Modelo de Gestão da Cooperação e suas Práticas Administrativas

\begin{tabular}{|c|c|c|}
\hline \multicolumn{3}{|c|}{ MODELO DE GESTÃO DA COOPERAÇÃO } \\
\hline Fases & $\begin{array}{l}\text { Práticas } \\
\text { administrativas }\end{array}$ & Descrição \\
\hline \multirow[t]{3}{*}{$\begin{array}{l}\text { Pré-desenvolvimento } \\
\text { da cooperação }\end{array}$} & $\begin{array}{l}\text { Definição do } \\
\text { portfólio de } \\
\text { projetos } \\
\text { cooperativos }\end{array}$ & $\begin{array}{l}\text { Os projetos considerados estratégicos que exigem } \\
\text { conhecimentos e competências que não estão disponíveis } \\
\text { internamente são então desenvolvidos com fontes externas; os } \\
\text { projetos cooperativos estão vinculados às competências centrais } \\
\text { da empresa. }\end{array}$ \\
\hline & $\begin{array}{l}\text { Seleção dos } \\
\text { parceiros } \\
\text { tecnológicos }\end{array}$ & $\begin{array}{l}\text { Para selecionar novos parceiros, a empresa avalia as indicações } \\
\text { das instituições que já são parceiras, as habilidades e as } \\
\text { competências científicas e de gestão dos potenciais parceiros e a } \\
\text { proximidade geográfica. }\end{array}$ \\
\hline & $\begin{array}{l}\text { Planejamento da } \\
\text { cooperação } \\
\text { tecnológica }\end{array}$ & $\begin{array}{l}\text { O escopo do projeto cooperativo; as metas e os prazos; os } \\
\text { recursos necessários para viabilizar a parceria e as fontes de } \\
\text { fomento; os procedimentos gerenciais a serem adotados e a } \\
\text { política de propriedade intelectual são aspectos que integram o } \\
\text { planejamento das parcerias da empresa. }\end{array}$ \\
\hline \multirow[t]{5}{*}{$\begin{array}{l}\text { Desenvolvimento da } \\
\text { cooperação }\end{array}$} & $\begin{array}{l}\text { Definição dos } \\
\text { contratos } \\
\text { cooperativos }\end{array}$ & $\begin{array}{l}\text { Para formalizar as parcerias, são normalmente estabelecidos } \\
\text { contratos de exclusividade, nos quais são esclarecidos a natureza } \\
\text { e os prazos dos projetos, as responsabilidades das partes e a } \\
\text { política de propriedade intelectual. }\end{array}$ \\
\hline & $\begin{array}{l}\text { Estruturação física } \\
\text { e financeira }\end{array}$ & $\begin{array}{l}\text { Os financiadores das parcerias são a própria empresa, o MCT, a } \\
\text { FINEP e a CAPES. São utilizados laboratórios e instalações da } \\
\text { empresa e da instituição parceira. }\end{array}$ \\
\hline & $\begin{array}{c}\text { Estruturação das } \\
\text { equipes de trabalho }\end{array}$ & $\begin{array}{l}\text { As equipes são formadas por estudantes, professores, técnicos e } \\
\text { funcionários administrativos e pelos gerentes de projetos da } \\
\text { empresa. Cada área temática de interesse da empresa possui um } \\
\text { gerente que é responsável pela interface empresa-universidade. }\end{array}$ \\
\hline & $\begin{array}{l}\text { Execução dos } \\
\text { projetos } \\
\text { cooperativos }\end{array}$ & $\begin{array}{l}\text { As metas do projeto são agora executadas e, se necessário, são } \\
\text { efetuadas mudanças. Durante a execução dos projetos há uma } \\
\text { interação freqüente da empresa com a academia e ocorre uma } \\
\text { comunicação contínua entre as partes envolvidas. }\end{array}$ \\
\hline & $\begin{array}{l}\text { Acompanhamento } \\
\text { das atividades } \\
\text { cooperativas }\end{array}$ & $\begin{array}{l}\text { O acompanhamento das parcerias é realizado pelos gerentes de } \\
\text { projetos e é efetivado pela avaliação de relatórios e por meio de } \\
\text { reuniões. Estes gerentes também informam à diretoria de P\&D a } \\
\text { evolução das projetos. }\end{array}$ \\
\hline
\end{tabular}

Continua 
Tabela 5 (continuação)

\begin{tabular}{|c|c|c|}
\hline \multirow[t]{3}{*}{$\begin{array}{l}\text { Pós-desenvolvimento } \\
\text { da cooperação }\end{array}$} & $\begin{array}{l}\text { Avaliação das } \\
\text { parcerias } \\
\text { tecnológicas }\end{array}$ & $\begin{array}{l}\text { São adotados pela empresa os seguintes critérios de avaliação: a } \\
\text { base de conhecimento da academia; a qualidade e a facilidade } \\
\text { da interação; a habilidade da instituição em compreender as } \\
\text { necessidades da empresa; a sua habilidade em gerar } \\
\text { conhecimentos que atendam às exigências tecnológicas da } \\
\text { empresa; e sua eficácia ao executar o projeto. }\end{array}$ \\
\hline & $\begin{array}{l}\text { Transferência de } \\
\text { conhecimento }\end{array}$ & $\begin{array}{l}\text { A transferência de conhecimento ocorre pelo contato direto } \\
\text { entre a empresa e a academia, pela contratação de alunos } \\
\text { envolvidos nas parcerias tecnológicas; e pelo treinamento } \\
\text { direcionado aos colaborados da área de } \mathrm{P} \& \mathrm{D} \text {, para que eles } \\
\text { possam internalizar os conhecimentos gerados na parceria. }\end{array}$ \\
\hline & $\begin{array}{l}\text { Garantia da } \\
\text { propriedade } \\
\text { intelectual }\end{array}$ & $\begin{array}{l}\text { Todas as inovações geradas de forma cooperativa são } \\
\text { patenteadas, e a titularidade é em nome da empresa e da } \\
\text { instituição parceira, sendo que não poderá haver licenciamento } \\
\text { para os concorrentes da empresa. }\end{array}$ \\
\hline
\end{tabular}

Nota. Fonte: Elaborada pelos autores.

Apesar de o modelo de gestão da Embraco estar alinhado às discussões teóricas apresentadas por Bonaccorsi e Piccaluga (1994), Prabhú, (1999), Mora-Valentin (2000), Schartinger et al. (2002), Barnes et al. (2002), Siegel et al. (2003), Mora-Valentin et al. (2004), Laursen e Salter (2004) e Debackere e Veugelers (2005), nota-se que alguns passos ainda precisam ser dados pela empresa, como exemplos: a instauração de uma visão mais sistêmica do processo de cooperação, para que as práticas administrativas adotadas sejam efetivadas interativamente; gestão participativa durante todas as fases dos projetos cooperativos, a fim de atingir os objetivos e interesses de ambas as partes; seleção de potenciais parceiros que atuam dentro das temáticas de P\&D de interesses da empresa; definição conjunta do escopo dos projetos; postura mais agressiva quanto à prospecção global de fontes de fomento à cooperação, seja financeira, fiscal ou estrutural; consenso entre os fluxos de trabalho da empresa e da universidade; gestão eficiente dos prazos dos projetos; avaliação e posterior registro dos resultados propriamente ditos das atividades de cooperação.

\section{CONSIDERAÇÕES FINAIS}

Diante das discussões teóricas apresentadas e levando-se em consideração o caso avaliado, observase que a Embraco gerencia a cooperação com fontes externas de tecnologia, a partir de um modelo de gestão formal, integrado por onze práticas administrativas que são processadas linearmente. Estas práticas gerenciais são basicamente efetivadas seqüencialmente em três fases: a fase de prédesenvolvimento da cooperação, na qual ocorre a definição dos projetos, a seleção dos parceiros e o planejamento das atividades; a fase de desenvolvimento da cooperação, onde os contratos são firmados, a infra-estrutura é organizada, e as atividades são executadas e acompanhadas; e a fase de pós-desenvolvimento da cooperação, na qual as atividades são avaliadas, o conhecimento é transferido, e a propriedade intelectual é garantida. Apenas as práticas de acompanhamento e de avaliação tendem a ocorrer de forma mais dinâmica, ao longo do processo de cooperação.

Especificamente, observou-se que os projetos de cooperação tecnológica possuem importância estratégica para a Embraco, e o foco central destes projetos é gerar cooperativamente conhecimentos que, posteriormente, possam ser aplicados nas atividades internas de $\mathrm{P} \& \mathrm{D}$, propiciando o desenvolvimento de inovações e adaptações tecnológicas. Deve-se, também, destacar que as atividades 
cooperativas da Embraco envolvem pesquisa, desenvolvimento e monitoramento tecnológico, e os principais mecanismos de cooperação adotados são os consórcios, a cooperação com universidades e companhias de outros segmentos de mercado, os projetos pontuais e os programas de pesquisa.

Além de apresentar as conclusões centrais do trabalho, deve-se também destacar que alguns passos ainda precisam ser dados pelo Embraco, para que as atividades de cooperação tecnológica possam ser plenamente gerenciadas e aproveitadas. Portanto, em futuro próximo, algumas ações deverão ser avaliadas com cautela pela empresa, como as discriminadas em seguida.

1) $\mathrm{O}$ desenvolvimento de indicadores de inovação que possam mensurar qualitativa e quantitativamente os resultados dos projetos cooperativos, pois atualmente não existem procedimentos formais para monitorar, filtrar e avaliar os resultados propriamente ditos da cooperação universidade-empresa.

2) A elaboração de um sistema de informação de suporte à gestão das parcerias que possibilite: o registro dos projetos que são desenvolvidos em todas as unidades (matriz e subsidiárias); o acompanhamento periódico das metas e dos prazos desses projetos; e o arquivamento das informações relativas aos projetos já finalizados, tais como o escopo e a duração deles, os objetivos, os resultados alcançados e os problemas enfrentados. Esse sistema facilitará o intercâmbio de informações e conhecimentos entre os projetos cooperativos desenvolvidos, tanto na matriz quanto nas subsidiárias.

3) A criação de uma robusta rede internacional de cooperação tecnológica também é uma opção estratégica que deve ser considerada pela empresa, porquanto, apesar de existirem parcerias internacionais expressivas, nota-se que o intercâmbio e a disseminação de conhecimentos entre matriz, subsidiárias e parceiros tecnológicos ainda não são explorados intensamente. Surge, então, o desafio de se criarem programas de pesquisa cooperativos mais amplos, nos quais as inovações possam ser criadas e difundidas mutuamente entre as unidades da empresa e os parceiros tecnológicos.

4) Verifica-se, também, a urgência em preparar melhor as subsidiárias, para que elas próprias possam optar pelas parcerias que melhor se adaptem às suas necessidades tecnológicas. A matriz da empresa também precisa acompanhar, contínua e formalmente, as atividades cooperativas das subsidiárias, para que os conhecimentos e as tecnologias gerados nessas atividades possam ser aproveitados por todas as unidades. Na ausência de um acompanhamento meticuloso, pode ocorrer duplicidade de esforços cooperativos, não sendo possível verificar se os resultados dos projetos cooperativos são, de fato, compartilhados entre as unidades produtivas.

5) O modelo de gestão da cooperação adotado também deverá sofrer adaptações e/ou melhorias, como a instauração de uma visão mais sistêmica do processo de cooperação; gestão participativa de todas as fases dos projetos; seleção de potenciais parceiros que atuam dentro das temáticas de P\&D de interesses da empresa; definição conjunta do escopo dos projetos; postura mais agressiva quanto à prospecção global por fontes de fomento à cooperação, seja financeira, fiscal ou estrutural; consenso entre os fluxos de trabalho da empresa e da universidade; gestão eficiente dos prazos dos projetos; avaliação e posterior registro dos resultados propriamente ditos das atividades cooperativas.

Por fim, é relevante frisar que a interação empresa-universidade não é solução mágica para as dificuldades e desafios da academia e da indústria; tampouco é processo fácil, sem resistências e antagonismos. O que se pode observar, a partir do caso apresentado, é que, a despeito de todas as dificuldades inerentes ao processo de cooperação tecnológica, é possível compatibilizar os interesses e as necessidades do setor acadêmico e os do setor da produção material, mediante a adoção de práticas gerenciais flexíveis e eficientes. Nesse sentido, as atividades acadêmicas e empresariais podem, e têm de ser compatíveis; no contexto atual, a universidade não se pode furtar a participar ativamente do processo de desenvolvimento econômico e social, como provedora de conhecimentos e de profissionais preparados para enfrentar a nova realidade; por outro lado, o segmento empresarial 
também precisa participar das discussões tecnocientíficas da atualidade, para fomentar o aprendizado organizacional e corroborar o desenvolvimento econômico-social do país. Em outras palavras, a cooperação empresa-universidade é grande propulsor da competitividade tecnológica e deve ser foco de atenção não só das empresas como também das universidades e do governo.

\section{Artigo recebido em 07.10.2007. Aprovado em 27.08.2008.}

\section{REFERÊNCIAS BIBLIOGRÁFICAS}

Barnes, T., Pashby, I., \& Gibbons, A. (2002). Effective university-industry interaction: a multi-case evolution of collaborative R\&D projects. European Management Journal, 20(3), 272-285.

Berkhout, A. J., Hartmann, D., Duin, P. V. D, \& Ortt, R. (2006). Innovating the innovation process. Technology Management, 34(3-4), 390-404.

Bonaccorsi, A., \& Piccaluga, A. A. (1994). Theoretical framework for de evaluation of universityindustry relationships. $R \& D$ Management, 24(3), 229-247.

Brito-Cruz, C. H. A (1999). Universidade, a empresa e a pesquisa que o país precisa. Revista Humanidades, 45, 15-29.

Cassiolato, J. E., \& Lastres, H. M. M. (2005). Tecnoglobalismo e o papel dos esforços de P,D\&I de multinacionais no mundo e no Brasil. Parcerias Estratégicas [Parte 4], 20, 1225-1246.

Chesnais, F. (1998). A mundialização do capital. São Paulo: Xamã.

Debackere, K., \& Veugelers, R. (2005). The role of academic technology transfer organizations in improving industry science links. Research Policy, 34(3), 321-342.

Edler, J., Krahmer, F. M., \& Reger, G. (2002). Changes in the strategic management of technology: results of a global benchmarking study. R\&D Management, 32(2), 149-164.

Empresa Brasileira de Compressores. (2007). Tecnologia. Recuperado em 2 agosto, 2007, de http://www.embraco.com.br/portugue/tecnologia.htm

Etzkowitz, H. (2004). The evolution of the entrepreneurial university. International Journal of Technology and Globalisation, 1(1), 64-77.

Etzkowitz, H., \& Leydesdorff, L. (2000). Le "mode 2" et la globalization des systèmes d'innovation "nationaux". Sociologie et sociétés, 32(1), 135-156.

Fleury, M. T. L. (1999). A relação universidade-empresa: desafios e oportunidades na geração e na disseminação do conhecimento. Revista de Administração da Universidade de São Paulo, 34(4), 32-45.

Freeman, C. (1991). Networks of innovators: a synthesis of research issues. Research Policy, 20(5), 499-514.

Freitas, H., \& Janissek, R. (2000). Análise léxica e análise de conteúdo: técnicas complementares, seqüenciais e recorrentes para exploração de dados qualitativos. Porto Alegre: Sagra Luzzatto.

Gil, A. C. (2002). Métodos e técnicas de pesquisa social. São Paulo: Atlas.

Instituto Brasileiro de Geografia e Estatística. (2007). Classificação nacional de atividade econômica. $\begin{array}{lllll}\text { Recuperado em } & 25 & \text { agosto, } & 2007,\end{array}$ 
http://www.cnae.ibge.gov.br/estrutura.asp?TabelaBusca=CNAE_110@CNAE\%201.0\%20/\%20 CNAE\%20FISCAL\%201.1@0@cnaefiscal@0

Laursen, K., \& Salter, A. (2004). Searching high and low: what types of firms use universities as a source of innovation? Research Policy, 33(8), 1201-1215.

Leydesdorff, L., Dolfsma, W., \& Panne, G. V. D. (2006). Measuring the knowledge base of an economy in terms of triple-helix relations among technology, organization, and territory'. Research Policy, 35(2), 181-199.

Leydesdorff, L., \& Meyer, M. (2006). Triple helix indicators of knowledge-based innovation systems: introduction to the special issue. Research Policy, 35(10), 1441-1449.

Martins, G. A. (2006). Estudo de caso: uma estratégia de pesquisa. São Paulo: Atlas.

Mora-Valentin, E. M. (2000). University-industry cooperation: a framework of benefits and obstacles. Industry \& Higher Education, 14(3), 165-172.

Mora-Valentin, E. M., Montoro-Sanchez, A., \& Guerra-Martin, L. A. (2004). Determinig factors in the success of R\&D cooperative agreements between firms and research organizations. Research Policy, 33(1), 17-40.

Motohashi, K. (2005). University-industry collaborations in Japan: the role of new technology-based firms in transforming the national innovation system. Research Policy, 34(5), 583-594.

Prabhú, G. N. (1999). Implementing university-industry joint product innovation projects. Technovation, 19(8), 495-505.

Reis, D. R. (2004). Gestão da inovação tecnológica. São Paulo: Manole.

Richardson, R. J. (1999). Pesquisa social: métodos e técnicas. São Paulo: Atlas.

Schartinger, D., Rammer, C., Ficher, M. M., \& Fohlich, J. (2002). Knowledge interations between universities and industry in Austria: sectoral patterns and determinants. Research Policy, 31(3), 303-328.

Segatto-Mendes, A. P. (2002, outubro). A cooperação universidade-empresa como uma das tendências para o crescimento tecnológico das organizações. Anais do Congresso Latino-Americano de Escolas de Administração, Porto Alegre, RS, Brasil, 37.

Siegel, D. S., Waldman, D. A., Atwater, L. E., \& Link, A. N. (2003). Commercial knowledge transfers from universities to firms: improving the effectiveness of university-industry collaboration. Journal of High Technology Management Research, 14(1), 111-133.

Sutz, J. (2000). The university-industry-government relations in Latin America. Research Policy, 29(2), 279-290. 